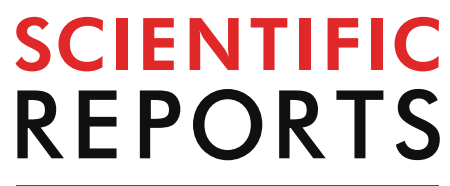

natureresearch

Check for updates

\title{
Vitamin D supplementation
} and the outcomes of critically ill adult patients: a systematic review and meta-analysis of randomized controlled trials

\author{
Shao-Huan Lan ${ }^{1,7}$, Chih-Cheng Lai ${ }^{2,7}$, Shen-Peng Chang ${ }^{3}$, Li-Chin Lu ${ }^{4}$, Shun-Hsing Hung ${ }^{5 \bowtie}$ \& \\ Wei-Ting Lin ${ }^{6 \bowtie}$
}

This meta-analysis assessed the association between vitamin $D$ supplementation and the outcomes of critically ill adult patients. A literature search was conducted using the PubMed, Web of Science, EBSCO, Cochrane Library, Ovid MEDLINE, and Embase databases until March 21, 2020. We only included randomized controlled trials (RCTs) comparing the efficacy of vitamin D supplementation with placebo in critically ill adult patients. The primary outcome was their 28-day mortality. Overall, 9 RCTs with 1867 patients were included. In the pooled analysis of the 9 RCTs, no significant difference was observed in 28 -day mortality between the vitamin $D$ supplementation and placebo groups $(20.4 \%$ vs $\left.21.7 \%, \mathrm{OR}, 0.73 ; 95 \% \mathrm{Cl}, 0.46-1.15 ; l^{2}=51 \%\right)$. This result did not change as per the method of vitamin $D$ supplementation (enteral route only: $19.9 \%$ vs $18.2 \%$, OR, $1.19 ; 95 \% \mathrm{Cl}, 0.88-1.57 ; I^{2}=10 \%$; intramuscular or intravenous injection route: $25.6 \%$ vs $40.8 \%, \mathrm{OR}, 0.48 ; 95 \% \mathrm{Cl}, 0.21-1.06 ; l^{2}=19 \%$ ) or daily dose (high dose: $20.9 \%$ vs $19.8 \%$, OR, $0.83 ; 95 \% \mathrm{Cl}, 0.51-1.36 ; l^{2}=53 \%$; low dose: $15.6 \%$ vs $21.3 \%, \mathrm{OR}, 0.74 ; 95 \% \mathrm{Cl}, 0.32-1.68 ; I^{2}=0 \%$ ). No significant difference was observed between the vitamin $D$ supplementation and placebo groups regarding the length of ICU stay (standard mean difference $[S M D],-0.30 ; 95 \% \mathrm{Cl},-0.61$ to $0.01 ; l^{2}=60 \%$ ), length of hospital stay (SMD, $-0.17 ; 95 \%$ $\mathrm{Cl},-041$ to $0.08 ; I^{2}=65 \%$ ), and duration of mechanical ventilation (SMD, $-0.41 ; 95 \% \mathrm{Cl},-081$ to 0.00 ; $P^{2}=72 \%$ ). In conclusion, this meta-analysis suggested that the administration of vitamin $\mathrm{D}$ did not provide additional advantages over placebo for critically ill patients. However, additional studies are needed to confirm our findings.

Vitamin D, a fat-soluble vitamin, is an essential nutrient in bone metabolism and calcium and phosphorus homeostasis. However, the system of vitamin D is complex, in which some novel pathways have been found for host response to vitamin $\mathrm{D}$ treatment including non-canonical pathways of vitamin $\mathrm{D}$ activation ${ }^{1,2}$ leading to production of non- or low-calcemic analogs ${ }^{3}$ and of lumisterol activation ${ }^{4}$. In clinical practice, vitamin $\mathrm{D}$ is used for the treatment of hyperproliferative skin diseases, hyperparathyroidism, and osteoporosis. Vitamin D also exhibits other non-skeletal pleiotropic properties, such as immunomodulatory, antimicrobial, cardiovascular, and muscular effects. Therefore, vitamin D deficiency is associated with many diseases including tuberculosis, nonalcoholic fatty liver disease, cardiovascular disease, and metabolic syndrome ${ }^{5-7}$. In the United States, adults aged 20-39 years are at the highest risk of vitamin D deficiency (the prevalence: $7.6 \%$; $95 \%$ CI: $6.0-9.6 \%)^{8}$. One

\footnotetext{
${ }^{1}$ School of Pharmaceutical Sciences and Medical Technology, Putian University, Putian 351100, China. ${ }^{2}$ Department of Internal Medicine, Kaohsiung Veterans General Hospital, Tainan Branch, Tainan, Taiwan. ${ }^{3}$ Yijia Pharmacy, Tainan 70846, Taiwan. ${ }^{4}$ School of Management, Putian University, Putian 351100, China. ${ }^{5}$ Division of Urology, Department of Surgery, Chi-Mei Hospital, Chia Li, Tainan, Taiwan. ${ }^{6}$ Department of Orthopedic, Chi Mei Medical Center, Tainan 71004, Taiwan. ${ }^{7}$ These authors contributed equally: Shao-Huan Lan and Chih-Cheng Lai. ${ }^{\square}$ email: e197948@yahoo.com.tw; aapriliaa@gmail.com
} 
study conducted in Europe showed that $13.0 \%$ of 55,844 European individuals showed average serum 25(OH) $\mathrm{D}$ concentrations of $<30 \mathrm{nmol} / \mathrm{L}^{9}$. In China, $30.6 \%$ of elderly people have vitamin $\mathrm{D}$ deficiency ${ }^{10}$.

In addition to its prevalence in the general population, vitamin D deficiency is common among critically ill patients. Lee et al. showed that $64.5 \%(\mathrm{n}=120)$ of critically ill surgical patients had serum $25(\mathrm{OH}) \mathrm{D}$ concentrations of $<20 \mathrm{nmol} / \mathrm{L}^{11}$, and Higgins et al. reported that $26 \%(50 / 196)$ of patients admitted to a medical/surgical intensive care unit (ICU) had vitamin D levels of $\leq 30 \mathrm{nmol} / \mathrm{L}^{12}$. A retrospective cohort study showed that $54 \%$ $(65 / 121)$ of patients with severe sepsis or septic shock had vitamin D levels lower than $15 \mathrm{mg} / \mathrm{mL}^{13}$, and another prospective multicenter study demonstrated vitamin D deficiency in $78.8 \%$ (197/250) of patients ${ }^{14}$. Furthermore, several studies document that vitamin $\mathrm{D}$ deficiency could be associated with poor outcomes in critically ill patients ${ }^{12,13,15-18}$. To improve the outcomes of critically ill patients, vitamin D supplementation was proposed for ICU patients. Several randomized controlled trials (RCTs) were conducted to investigate the effects of vitamin D supplementation on the outcomes of critically ill patients. However, their results are conflicting ${ }^{19-28}$. Some studies showed that vitamin D supplementation demonstrated positive effects by decreasing the length of hospital stay ${ }^{23}$, duration of mechanical ventilation $(\mathrm{MV})^{26,27}$, and mortality rate ${ }^{24,27}$. However, some studies ${ }^{11,20,21,25,29,30}$ reported no change in the outcomes of critically ill patients. Even 2 meta-analyses, the included studies of which were published before $2017^{31,32}$, provided inconsistent findings. Since 2017 , four more RCTs ${ }^{24-27}$ have reported their findings. Therefore, we conducted an updated meta-analysis of RCTs to assess the association between vitamin D supplementation and the outcomes of critically ill patients.

\section{Methods}

Study search and selection. We conducted a literature review using the databases of PubMed, Embase, Web of Science, EBSCO, Cochrane Library, Ovid Medline, Embase, and Proquest until March 21, 2020. The following search terms were used: "intensive care" "ICU," "critically-ill," "vitamin D," "calcitriol," "Cholecalciferol”," "ergocalciferol*," and "RCT." Our meta-analysis only included RCTs that investigated the clinical efficacy of vitamin D supplementation compared with placebo for critically ill adult patients. The supplementation could be done in different ways, such as oral, enteral, or parenteral vitamin D administration as 1, 25-dihydroxyvitamin D (calcitriol) or 25-hydroxyvitamin D (cholecalciferol). Two authors (Lan SH and Chang SP) searched for related studies and examined the risk of bias in each study using the Cochrane Risk of Bias Assessment tool ${ }^{33}$. When they had different opinions, a third author (Lai CC) helped resolve the issue. Data, including the year of publication, study design, study location and duration, demographic characteristics of critically ill patients, regimen of vitamin D, patient outcomes, and adverse events, were extracted from each included study. This study followed the Preferred Reporting Items for Systematic Reviews and Meta-analyses (PRISMA) reporting guidelines.

Definitions and outcomes. Critically ill patients were defined as that the patients with acute respiratory failure required mechanical ventilation or the patients required ICU hospitalization. The primary outcome of the current study was the patients' 28-day mortality. If data on 28-day mortality were not available, hospital mortality was used in the meta-analysis. Secondary outcomes included the length of ICU and hospital stay and the duration of MV. Doses of $\geq 300,000$ and $<300,000$ IU of vitamin D daily were defined as high and low doses, respectively, as per a previous study ${ }^{34}$.

Statistical analysis. We used Review Manager software (The Cochrane Collaboration 2008, Copenhagen) to develop a random-effects model and derive the pooled estimates and their associated $95 \%$ CIs. The odds ratio (OR) was used to evaluate the outcome of 28-day mortality. Standardized mean differences (SMDs) and 95\% CIs were computed for continuous variables including length of ICU and hospital stay and the duration of MV.

\section{Results}

Study selection. Our search yielded 444 studies in total from online databases from PubMed $(\mathrm{n}=56)$, Web of Science $(n=71)$, EBSCO $(n=27)$, Cochrane library $(n=107)$, Ovid MEDLINE $(n=74)$, and Embase $(n=85)$; 272 duplicate studies were excluded. The remaining 172 articles were identified. Moreover, 142 studies were found to be irrelevant after the title and abstract were screened, and 19 studies were found to be irrelevant after the full text was screened. Eventually, $9 \mathrm{RCTs}^{19-27}$ were included in this meta-analysis (Fig. 1, Appendix 1).

Study characteristics. Five RCTs ${ }^{19,21,22,26,27}$ were conducted in a single center, and three $\mathrm{RCTs}^{20,23,24}$ were conducted in two centers. Only one $\mathrm{RCT}^{25}$ was a multicenter study (Table 1). Four studies ${ }^{20,22,23,25}$ were conducted in the United States, three ${ }^{24,26,27}$ were in Iran, and two ${ }^{19,21}$ in Austria. Overall, these nine RCTs included a total of 1,640 critically ill patients. Three RCTs ${ }^{19,21,25}$ only enrolled patients with vitamin D levels $\leq 20 \mathrm{ng} / \mathrm{mL}$, and two studies ${ }^{26,27}$ enrolled patients with vitamin D levels $\leq 20 \mathrm{ng} / \mathrm{mL}$. Vitamin D was administered through the enteral route in five studies ${ }^{19,21-23,25}$, through intravenous or intramuscular injection in three ${ }^{20,24,27}$, and both routes in one ${ }^{26}$. Single-dose regimens of vitamin D were used in six studies ${ }^{19,20,22,24,25,27}$ and multidose regimens in three studies ${ }^{21,23,26}$. Almost all risks of bias were low in each study. The study by Miroliaee et al. ${ }^{24}$ and Hasanloei et al. ${ }^{26}$ had a high risk of allocation, and detection bias. The publication bias is shown in a funnel plot (Fig. 2).

Primary outcome. In the pooled analysis of nine RCTs, no significant difference was observed in 28-day mortality between the vitamin D supplementation and placebo groups $(20.4 \%$ vs $21.7 \%, \mathrm{OR}, 0.73 ; 95 \% \mathrm{CI}$, $0.46-1.15 ; I^{2}=51 \%$, Fig. 3 ). A sensitivity analysis performed after excluding individual studies did not change this result. Similarly, in the subgroup analysis of RCTs that enrolled only patients with vitamin D deficiency, no significant differences were observed in mortality $\left(21.4 \%\right.$ vs $\left.19.7 \%, \mathrm{OR}, 0.93 ; 95 \% \mathrm{CI}, 0.57-1.52 ; I^{2}=58 \%\right)$. This 

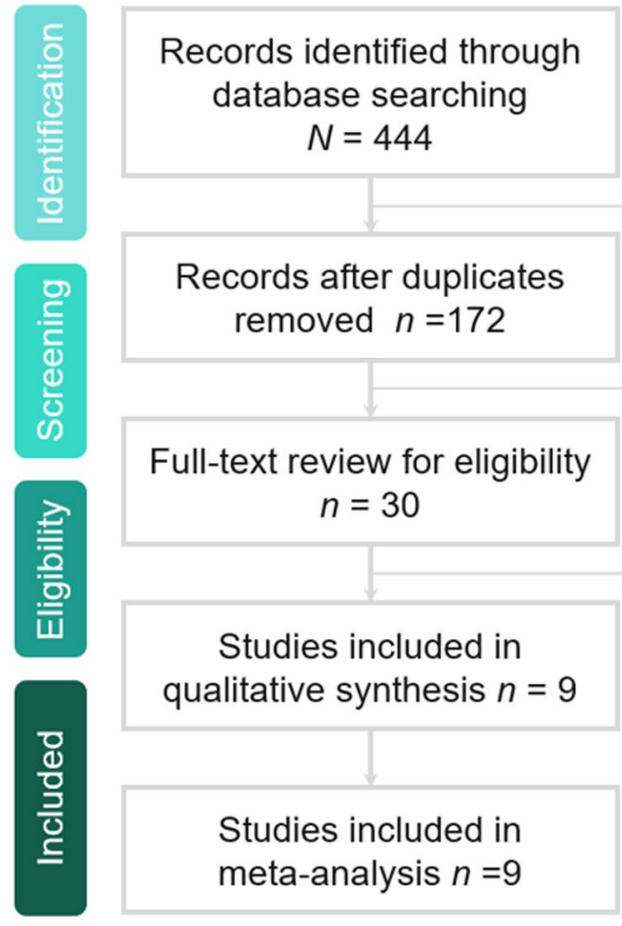

Duplicated records excluded $n=272$

Excluded by title and abstract $n=142$

Figure 1. Flowchart of study selection.

\begin{tabular}{|c|c|c|c|c|c|}
\hline Study, publish year & Study sites & Study duration & No of patients & Study population & Intervention \\
\hline Amrein et al., 2011 & Single center in Austria & $2009-2010$ & 25 & $\begin{array}{l}\text { Adult patients expected to stay in the ICU for } \\
48 \mathrm{~h} \text { or more, and had a } 25 \text {-hydroxyvitamin } \\
\text { D level } \leq 20 \mathrm{ng} / \mathrm{mL}\end{array}$ & Single enteral dose of vitamin D3 540,000 IUs \\
\hline Leaf et al., 2014 & Two centers in USA & 2013 & 67 & $\begin{array}{l}\text { ICU adult patients with severe sepsis or } \\
\text { septic shock and presence of an arterial or } \\
\text { central venous catheter }\end{array}$ & Single intravenous dose of calcitriol $2 \mu \mathrm{g}$ \\
\hline Amrein et al., 2014 & Single center in Austria & $2012-2015$ & 475 & $\begin{array}{l}\text { Patients who were } 18 \text { years or older expected } \\
\text { to stay in the ICU for } 48 \mathrm{~h} \text { or more, and had } \\
\text { a } 25 \text {-hydroxyvitamin D level } \leq 20 \mathrm{ng} / \mathrm{mL}\end{array}$ & $\begin{array}{l}\text { Single enteral dose of vitamin D3 } 540,000 \text { IUs } \\
\text { followed by monthly maintenance doses of } \\
90,000 \text { IU for } 5 \text { months }\end{array}$ \\
\hline Quraishi et al., 2015 & Single center in USA & 2014 & 30 & $\begin{array}{l}\text { Adult patients admitted to medical or surgi- } \\
\text { cal ICU and with } 24 \mathrm{~h} \text { of new onset sepsis }\end{array}$ & $\begin{array}{l}\text { Single enteral dose of vitamin D3 200,000 IU } \\
\text { or 400,000 IUs }\end{array}$ \\
\hline Han et al., 2016 & Two centers in USA & NR & 30 & $\begin{array}{l}\text { Adult patients received care in ICU, expected } \\
\text { to require MV for } \geq 72 \mathrm{~h} \text { and expected to } \\
\text { survive and remain in ICU for } \geq 96 \mathrm{~h}\end{array}$ & $\begin{array}{l}\text { Different vitamin D3 enteral doses divided } \\
\text { more than } 5 \text { consecutive days ( } 50,000 \text { IU or } \\
100,000 \text { IU daily) }\end{array}$ \\
\hline Miroliaee et al., 2017 & Two centers in Iran & $2014-2015$ & 46 & $\begin{array}{l}\text { Adult patients who had been diagnosed } \\
\text { wtih ventilator-associated pneumonia and } \\
25 \text {-hydroxyvitamin D level } \leq 30 \mathrm{ng} / \mathrm{mL}\end{array}$ & 300,000 IUs of intramuscular vitamin D \\
\hline Ginde et al., 2019 & 44 centers in USA & $2017-2018$ & 1,078 & $\begin{array}{l}\text { Adult patients admitted to ICU and had } \\
25 \text {-hydroxyvitamin D level } \leq 20 \mathrm{ng} / \mathrm{mL}\end{array}$ & a single enteral dose of 540,000 IU1 \\
\hline Hasanloei et al., 2019 & Single center in Iran & $2017-2018$ & 72 & $\begin{array}{l}\text { Traumatic injury admitted to ICU with a } \\
\text { 25(OH)D serum level between } 10 \text { and } 30 \mathrm{ng} / \\
\mathrm{mL}\end{array}$ & $\begin{array}{l}\text { Oral 50,000 IU cholecalciferol daily for } \\
6 \text { days, or one intramuscular injection of } \\
300,000 \text { IU of cholecalciferol }\end{array}$ \\
\hline Miri et al., 2019 & Single center in Iran & NA & 40 & $\begin{array}{l}\text { Mechanically ventilated patient admitted } \\
\text { to ICU }\end{array}$ & $\begin{array}{l}\text { intramuscular injection of 300,000 IU } \\
\text { vitamin D }\end{array}$ \\
\hline
\end{tabular}

Table 1. Characteristics of the randomized placebo-controlled trials included in the meta-analysis. NA not applicable.

result did not change as per the method of vitamin D supplementation (enteral route only: $19.9 \%$ vs $18.2 \%$, OR, $1.19 ; 95 \%$ CI, $0.88-1.57 ; I^{2}=10 \%$; intramuscular or intravenous injection route: $25.6 \%$ vs $40.8 \%$, OR, 0.48 ; $95 \%$ CI, $0.21-1.06 ; I^{2}=19 \%$ ) or the daily dose (high dose: $20.9 \%$ vs $19.8 \%$, OR, 0.83 ; $95 \%$ CI, $0.51-1.36 ; I^{2}=53 \%$; low dose: $15.6 \%$ vs $21.3 \%$, OR, $0.74 ; 95 \%$ CI, $0.32-1.68 ; I^{2}=0 \%$ ). The similar trend was observed for subgroup with baseline vitamin D deficiency (19.3\% vs $19.1 \%$, OR, 0.80; $95 \% \mathrm{CI}, 0.48-1.46 ; I^{2}=63 \%$ ). Finally, although the studies conducted from 2016 to 2019 seems to have a better outcome than those from 2011 to 2015 , the pooled analysis of 5 studies conducted from 2016 to 2019 still did not show the significant difference between vit D and placebo group (OR, 0.50; 95\% CI, 0.18-1.34, I2=0.70\%). 


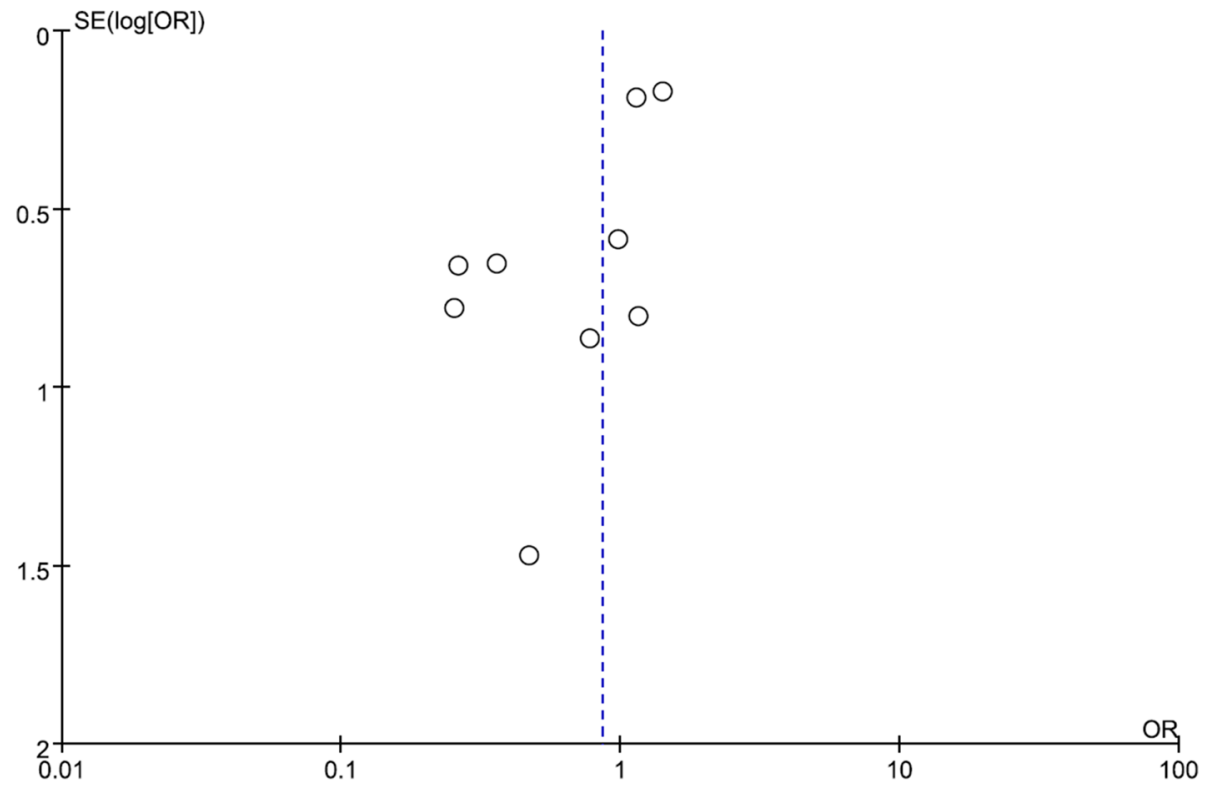

Figure 2. Funnel plot for comparison.

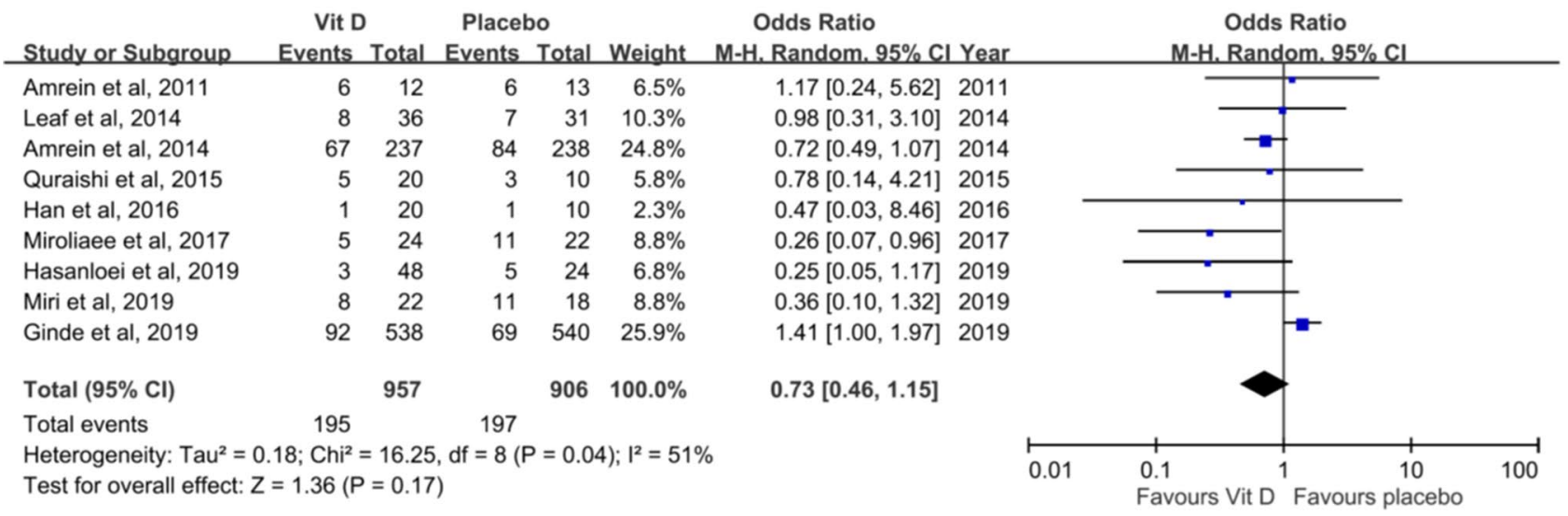

Figure 3. Effect of vitamin D on 28-day mortality.

Secondary outcome. The pooled analysis of seven studies ${ }^{19-23,26,27}$ reported no significant difference in the length of ICU stay between the vitamin D supplementation and placebo groups (SMD, $-0.30 ; 95 \% \mathrm{CI},-0.61$ to $0.01 ; I^{2}=60 \%$ )(Fig. 4). Analysis of six studies ${ }^{19-23,25}$ reported no significant difference in the length of hospital stay between the vitamin D supplementation and placebo groups (SMD, $-0.17 ; 95 \% \mathrm{CI},-041$ to $0.08 ; I^{2}=65 \%$ ) (Fig. 4). Six studies ${ }^{19-21,23,26,27}$ reported no significant difference in the duration of MV between both groups (SMD, $-0.41 ; 95 \% \mathrm{CI},-0.81$ to $0 ; I^{2}=72 \%$ )(Fig. 4). A subgroup analysis showed that high-dose vitamin D supplementation did not change length of ICU stay (SMD, $-1.82 ; 95 \% \mathrm{CI},-5$ to $1.35 ; I^{2}=99 \%$ ), length of hospital stay (SMD, $-0.09 ; 95 \% \mathrm{CI},-0.25$ to $0.06 ; I^{2}=31 \%$ ), and duration of MV (SMD, $-0.42 ; 95 \% \mathrm{CI},-0.92$ to 0.07 ; $I^{2}=70 \%$ ). Similarly, low-dose vitamin D did not change length of ICU stay (SMD, 0.29; $95 \% \mathrm{CI},-2.43$ to 3 ; $I^{2}=97 \%$ ), length of hospital stay (SMD, $-0.54 ; 95 \% \mathrm{CI},-1.45$ to $0.36 ; I^{2}=78 \%$ ), and duration of MV (SMD, -0.65 ; $95 \% \mathrm{CI},-1.66$ to $\left.0.37 ; I^{2}=87 \%\right)$.

\section{Discussion}

This meta-analysis included nine RCTs with 1867 patients to compare the efficacy and safety of vitamin D supplementation with placebo in critically ill patients. The outcome was numerically better in the vitamin D supplementation group than control group, which may suggest biologically significant trends favoring vitamin D supplementation, however, these differences did not reach statistical significance. Overall, our results suggested that vitamin D supplementation did not significantly improve the outcomes of critically ill patients, which was supported by the following evidence. First, 28-day mortality did not change with vitamin D supplementation in the pooled analysis of 9 RCTs. Second, this difference remained unchanged in the sensitivity test. Third, we also found no significant improvement in the mortality of critically ill patients with vitamin D deficiency in the 


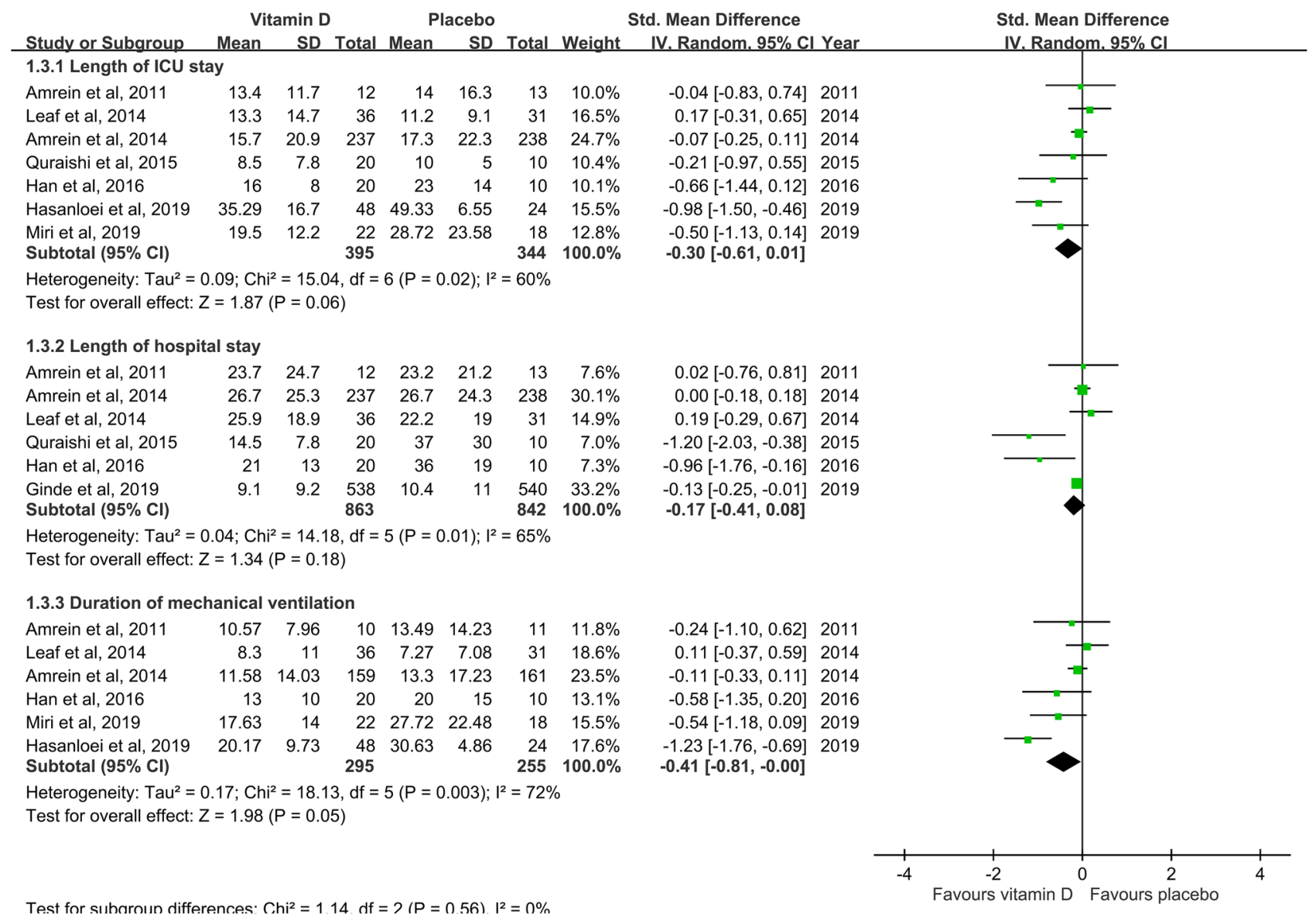

Figure 4. Effect of vitamin $\mathrm{D}$ on length of intensive care unit and hospital stay and the duration of mechanical ventilation.

subgroup analysis. Fourth, compared with the placebo group, we found no significant difference in mortality in the vitamin D supplementation group with either enteral or injection administration of vitamin D and with administration of low- or high-dose vitamin D. Finally, we assessed the effect of vitamin D on the length of ICU and hospital stay and MV duration and found no significant difference between the vitamin D supplementation and placebo groups. Moreover, no difference was observed in the subgroup analysis of high and low doses of vitamin $\mathrm{D}$. The aforementioned findings indicate that compared with placebo, the vitamin $\mathrm{D}$ supplementation is not associated with lower mortality in critically ill patients.

Our findings are consistent with those of a meta-analysis by Langlois et al. ${ }^{32}$, in which they included six RCTs of 695 patients, and they found that vitamin D did not reduce the mortality, length of ICU and hospital stay, and period on a ventilator. However, another meta-analysis by Putzu et al. ${ }^{31}$ including 7 studies of 716 patients between 2011 and 2016 showed that vitamin D supplementation was associated with lower mortality compared with placebo (OR, 0.70 ; $95 \% \mathrm{CI}, 0.50-0.98, I^{2}=0$ ). This difference could be because we included a recent largescale study of more than 1,000 patients by Ginde et al. ${ }^{25}$, in which the administration of high-dose vitamin D did not provide an additional benefit with respect to clinical outcomes, including mortality. Moreover, the data of clinical outcomes in the analysis by Putzu et al. ${ }^{31}$ had been reported by only 3 of 4 studies, which may limit the generalizability of their findings. Conversely, our study included more patients, more updated studies, and more subgroup analyses than previous studies ${ }^{31,32}$. In addition, all of our analyses showed consistent findings. Therefore, our findings provide stronger evidence regarding the effect of vitamin D supplementation on the outcomes of critically ill patients than previous studies.

However, this study had several limitations. Although this study focused on critically ill patients, their clinical characteristics are heterogeneous. Some were admitted to the ICU for traumatic injury, and some had ventilatorassociated pneumonia. The criteria of vitamin D deficiency varied across studies, and the disease severity of the study patients also differed. Therefore, potential positive effects of vitamin D supplementation on the patient outcomes could not be found in this pooled analysis. In addition, only limited studies reported the vit D3 level after treatment and their level increased after treatment. Thus, we cannot assess the association between the level of vitamin D after treatment and the clinical outcome. Further studies are warranted to discover specific populations who can benefit from vitamin D supplementation ${ }^{35}$. 


\section{Conclusion}

This meta-analysis suggested that the administration of vitamin D did not provide additional advantages over placebo for critically ill patients. However, additional studies are needed to confirm our findings.

Received: 4 May 2020; Accepted: 5 August 2020

Published online: 31 August 2020

\section{References}

1. Slominski, A. T. et al. In vivo evidence for a novel pathway of vitamin D3 metabolism initiated by P450scc and modified by CYP27B1. FASEB. J. 26, 3901-3915 (2012).

2. Slominski, A. T. et al. Detection of novel CYP11A1-derived secosteroids in the human epidermis and serum and pig adrenal gland. Sci. Rep. 5, 14875 (2015).

3. Slominski, A. T. et al. Novel activities of CYP11A1 and their potential physiological significance. J. Steroid Biochem. Mol. Biol. 151, 25-37 (2015).

4. Slominski, A. T. et al. Characterization of a new pathway that activates lumisterol in vivo to biologically active hydroxylumisterols. Sci. Rep. 7, 11434 (2017).

5. Alagacone, S., Verga, E., Verdolini, R. \& Saifullah, S. M. The association between vitamin D deficiency and the risk of resistant hypertension. Clin. Exp. Hypertens. 42, 177-180 (2020).

6. Wang, C. Y. et al. Association between vitamin D and latent tuberculosis infection in the United States: NHANES, 2011-2012. Infect. Drug Resist. 12, 2251-2257 (2019).

7. Kim, Y. S., Hwang, J. H. \& Song, M. R. The association between vitamin D deficiency and metabolic syndrome in Korean adolescents. J. Pediatr. Nurs. 38, e7-e11 (2018).

8. Herrick, K. A. et al. Vitamin D status in the United States, 2011-2014. Am. J. Clin. Nutr. 110, 150-157 (2019).

9. Cashman, K. D. et al. Vitamin D deficiency in Europe: Pandemic?. Am. J. Clin. Nutr. 103, 1033-1044 (2016).

10. Wei, J., Zhu, A. \& Ji, J. S. A comparison study of vitamin D deficiency among older adults in China and the United States. Sci. Rep. 9, 19713 (2019).

11. Lee, J. H., Doo, S. R., Kim, D., Park, Y. K., Park, E. J. \& Lee, J. M. Vitamin D deficiency and mortality among critically ill surgical patients in an urban Korean hospital. Int. J. Vitam. Nutr. Res. 1-8 (2020).

12. Higgins, D. M. et al. Relationship of vitamin D deficiency to clinical outcomes in critically ill patients. JPEN. J. Parenter. Enteral. Nutr. 36, 713-720 (2012)

13. Rech, M. A., Hunsaker, T. \& Rodriguez, J. Deficiency in 25-hydroxyvitamin D and 30-day mortality in patients with severe sepsis and septic shock. Am. J. Crit. Care. 23, e72-79 (2014).

14. Anwar, E. et al. Burden and outcome of vitamin D deficiency among critically ill patients: A prospective study. Nutr. Clin. Pract. 32, 378-384 (2017).

15. Zapatero, A. et al. Severe vitamin D deficiency upon admission in critically ill patients is related to acute kidney injury and a poor prognosis. Med. Intensiva. 42, 216-224 (2018).

16. Kvaran, R. B., Sigurdsson, M. I., Skarphedinsdottir, S. J. \& Sigurdsson, G. H. Severe vitamin D deficiency is common in critically ill patients at a high northern latitude. Acta Anaesthesiol. Scand. 60, 1289-1296 (2016).

17. Guan, J. et al. A prospective analysis of hypovitaminosis D and mortality in 400 patients in the neurocritical care setting. J. Neurosurg. 127, 1-7 (2017).

18. Moraes, R. B. et al. Vitamin D deficiency is independently associated with mortality among critically ill patients. Clinics (Sao Paulo). 70, 326-332 (2015)

19. Amrein, K. et al. Short-term effects of high-dose oral vitamin D3 in critically ill vitamin D deficient patients: A randomized, double-blind, placebo-controlled pilot study. Crit. Care. 15, R104 (2011).

20. Leaf, D. E., Raed, A., Donnino, M. W., Ginde, A. A. \& Waikar, S. S. Randomized controlled trial of calcitriol in severe sepsis. Am. J. Respir. Crit. Care Med. 190, 533-541 (2014).

21. Amrein, K. et al. Effect of high-dose vitamin D3 on hospital length of stay in critically ill patients with vitamin D deficiency: the VITdAL-ICU randomized clinical trial. JAMA 312, 1520-1530 (2014).

22. Quraishi, S. A. et al. Effect of cholecalciferol supplementation on vitamin D status and cathelicidin levels in sepsis: A randomized, placebo-controlled trial. Crit. Care Med. 43, 928-937 (2015).

23. Han, J. E. et al. High dose vitamin D administration in ventilated Intensive Care Unit patients: A pilot double blind randomized controlled trial. J. Clin. Transl. Endocrinol. 4, 59-65 (2016).

24. Miroliaee, A. E. et al. Effect of vitamin D supplementation on procalcitonin as prognostic biomarker in patients with ventilator associated pneumonia complicated with vitamin D deficiency. Iran. J. Pharm. Res. 16, 1254-1263 (2017).

25. Ginde, A. A. et al. Early high-dose vitamin D3 for critically ill, vitamin D-deficient patients. N. Engl. J. Med. 381, 2529-2540 (2019).

26. Hasanloei, M. A. V. et al. Effect of oral versus intramuscular vitamin D replacement on oxidative stress and outcomes in traumatic mechanical ventilated patients admitted to intensive care unit. Nutr. Clin. Pract. 35, 545-558 (2020).

27. Miri, M., Kouchek, M., Rahat, Dahmardeh. A. \& Sistanizad, M. Effect of high-dose vitamin D on duration of mechanical ventilation in ICU patients. Iran J. Pharm. Res. 18, 1067-1072 (2019).

28. Karsy, M., Guan, J., Eli, I., Brock, A. A., Menacho, S. T. \& Park, M. S. The effect of supplementation of vitamin D in neurocritical care patients: RandomizEd Clinical TrIal oF hYpovitaminosis D (RECTIFY). J. Neurosurg. 1-10 (2019).

29. Leclair, T. R. et al. Vitamin D supplementation in mechanically ventilated patients in the medical intensive care unit. JPEN. J. Parenter. Enteral. Nutr. 43, 1037-1043 (2019).

30. Viglianti, E. M., Zajic, P., Iwashyna, T. J. \& Amrein, K. Neither vitamin D levels nor supplementation are associated with the development of persistent critical illness: A retrospective cohort analysis. Crit. Care Resusc. 21, 39-44 (2019).

31. Putzu, A. et al. Vitamin D and outcomes in adult critically ill patients. A systematic review and meta-analysis of randomized trials. J Crit Care. 38, 109-114 (2017).

32. Langlois, P. L., Szwec, C., D’Aragon, F., Heyland, D. K. \& Manzanares, W. Vitamin D supplementation in the critically ill: A systematic review and meta-analysis. Clin. Nutr. 37, 1238-1246 (2018).

33. Higgins, J. P. et al. The Cochrane Collaboration's tool for assessing risk of bias in randomised trials. BMJ 343, d5928 (2011).

34. Kearns, M. D., Alvarez, J. A. \& Tangpricha, V. Large, single-dose, oral vitamin D supplementation in adult populations: A systematic review. Endocr. Pract. 20, 341-351 (2014).

35. Martucci, G. et al. Trying to identify who may benefit most from future vitamin D intervention trials: A post hoc analysis from the VITDAL-ICU study excluding the early deaths. Crit. Care 23, 200 (2019). 


\section{Author contributions}

L.S.H. and L.C.C. wrote the main manuscript. C.S.P. and L.L.C. data collection and anlaysis. H.S.H. and L.W.T. critical review and supervision.

\section{Competing interests}

The authors declare no competing interests.

\section{Additional information}

Supplementary information is available for this paper at https://doi.org/10.1038/s41598-020-71271-9.

Correspondence and requests for materials should be addressed to S.-H.H. or W.-T.L.

Reprints and permissions information is available at www.nature.com/reprints.

Publisher's note Springer Nature remains neutral with regard to jurisdictional claims in published maps and institutional affiliations.

(c) (1) Open Access This article is licensed under a Creative Commons Attribution 4.0 International cc) License, which permits use, sharing, adaptation, distribution and reproduction in any medium or format, as long as you give appropriate credit to the original author(s) and the source, provide a link to the Creative Commons licence, and indicate if changes were made. The images or other third party material in this article are included in the article's Creative Commons licence, unless indicated otherwise in a credit line to the material. If material is not included in the article's Creative Commons licence and your intended use is not permitted by statutory regulation or exceeds the permitted use, you will need to obtain permission directly from the copyright holder. To view a copy of this licence, visit http://creativecommons.org/licenses/by/4.0/.

(C) The Author(s) 2020 